persistent cough following radiotherapy. An inhalation of lignocaine relieved the cough within two hours and the effect continued for a week when a further inhalation was given. Since that time there has been no recurrence of the severe coughing fits.

Each of these patients obtained relief with lignocaine $400 \mathrm{mg}$ in saline administered via a Bird Micronebulizer. Salbutamol 2-5 mg was given by wet inhalation immediately before each treatment. It is our impression that mucus clearance was not impaired in these three patients. From this very limited experience we would not withhold lignocaine aerosol treatment in any patient who had distressing and otherwise uncontrollable cough and was suffering a fatal illness. We would agree with you that further evaluation of this technique is necessary in other types of illness giving rise to severe cough, particularly until the possible effects on mucus clearance is better understood.

C J STEWART T J COADY

Ipswich Hospital,

Ipswich

' Howard, P, et al, British fournal of Diseases of the Chest, 1977, 71, 19.

\section{Randomised clinical trials}

SIR,-Your leading article (14 May, p 1238) presents a good case for randomised clinical trials (RCTs). Alas, I feel that many investigators will still be unconvinced, arguing that non-randomised trials are justified if no sources of bias can be identified. Thus, I would like to present some evidence that bias can exist without any apparent explanation.

In the United States cancer chemotherapy co-operative groups it is common practice to include the same control treatment in consecutive RCTs. At the statistical laboratory in Buffalo, New York, I identified 19 such pairs of trials, mostly in advanced lung cancer, and compared the annual death rates of the two groups of patients on the same treatment:

The trials were fairly large, most having over 100 patients per treatment, and there were no known sources of bias. One would have expected little change in death rates on the same treatment from one trial to the next, whereas, in fact, the changes ranged from $-46 \%$ to $+24 \%$. In four instances the change was statistically significant at the $5 \%$ level (using a two-sided F-test for comparing two exponential death rates) and a further six changes were significant at the $20 \%$ level. Such marked evidence of differences between trials indicates that any comparison of treatments not within an RCT must be deemed highly suspect.

Regarding the failure to achieve sufficient patients, a current survey on the size of RCTs conducted by P Armitage, D A G Galton, and myself provides some interesting evidence. From a random sample of 50 cancer trials registered with UICC during 1972-5 our preliminary results based on 30 replies to a questionnaire indicate a median accrual rate of
34 per annum (total on all treatments) and a median of 5 years' accrual to achieve the prespecified number of patients. Evidently many will not achieve their accrual targets, so that although the design and execution of these trials were on the whole satisfactory a substantial number will prove inconclusive owing to the failure to make a realistic assessment of patient accrual.

This survey also showed that nearly all trials have repeated analyses of results, the most common interval between analyses being 6 months. Neither fixed nor sequential designs cope satisfactorily with such periodic assessments, but some recent developments in "group sequential" designs do provide a proper statistical basis for this approach. ${ }^{1-3} \mathrm{~A}$ further point from the survey was that two-thirds of trials incorporated stratification for prognostic factors in the randomisation. Thus your leading article's declaration that stratification is unnecessary is not being followed, and I think this is sensible in view of the fact that retrospective adjustment in analysis requires rather sophisticated statistical methods and even these are useless in cases of severe imbalance.

Also, I think the suggestion of an unequal randomisation (say, a 2:1 ratio), whereby a greater proportion of patients receive the new treatment, is to be encouraged. This is especially true if there are suitable historical data on the old treatment, since there exist statistical methods for incorporating such extra information into the trial's design and analysis. ${ }^{4}$ Lastly, I think the conversion of investigators to RCTs would be enhanced considerably if medical journals took a firmer stance in refusing to publish the results of non-randomised studies when an RCT was appropriate.

Stuart J Pocock

Medical Computing and Statistics

Group,

Medical School,

Edinburgh

McPherson, K, New England fournal of Medicine, 1974, 290, 50

${ }_{3}^{2}$ Pocock, S J, Biometrika, 1977 (in press)

+ Pocock, S J, fournal of Chronic Diseases, 1976, 29, 175.

\section{Delivery of postgraduate education}

SIR,-Professor A H Crisp (28 May, p 1397) has illustrated admirably the dilemma that faces many university departments in trying to strike a balance between undergraduate and postgraduate teaching responsibilities. In Wessex we were more fortunate than Professor Crisp in that a well-established postgraduate teaching programme existed long before the medical school at Southampton was opened, and to maintain the high quality of this programme academic sessions were specifically allocated for this purpose. Nevertheless, problems still persist, and in addition to the salaried sessional commitments by clinical tutors, suggested by Professor Crisp, a reappraisal of the teaching responsibilities of academic staff is necessary.

Although for historical and administrative reasons university clinical departments are funded according to their undergraduate teaching commitments) it is impossible (and inappropriate) for them not to be associated with postgraduate training. This should be recognised as a formal commitment to maintaining academic standards through their region. This commitment can to some extent be balanced by greater involvement of clinical teachers in undergraduate teaching. In our undergraduate teaching course in psychiatry we involve many consultants throughout the region, who devote considerable time and effort but who receive no recognition apart from the title of honorary clinical teacher. Formal recognition is needed of these changes in the job descriptions of both academic and clinical staff in addition to the extra funding that Professor Crisp suggests if we are to maintain a healthy integration between academic and clinical teaching responsibilities.

P J TYRER

General Hospital, Southampton

\section{Management of elderly demented patients}

SIR,-Your leading article (21 May, p 1301) on the management of elderly demented patients is aptly coloured in pessimistic lines familiar to those who have dealt with such patients and families. Having referred to a recent conference ${ }^{1}$ you lapse immediately into an attitude of caring for what seems to be assumed to be an a priori irreversible state. I wish to make two points.

(1) Although you mention "accurate diagnosis," this is quickly passed over. Recent work $^{2} 3$ indicates that a reversible cause for dementia is present in between 10 and $20 \%$ of patients referred to both specialist units and district general hospitals provided that investigation is adequate. Age alone is no guarantee that dementia is caused by irrevocable cerebral degenerative pathology. Such facts are politically unpalatable in times of stringency, because the tests necessary to the proper study of demented patients include time-consuming and expensive metabolic and neuroradiological investigations, not least the EMI scan. It is, however, our professional duty to patients to indicate clearly that unless these methods are applied to the vast numbers involved (at least $5 \%$ of the over- $65 \mathrm{~s}$, who number several million in the UK) many will be thrown on to the scrap heap and will require unnecessarily the expensive facilities of hospitals, hostels, and day centres your article describes so well.

(2) In discussing management you fall back on the trendy euphemism of the caring team (sic). You say, "the doctor's role is as a member of the caring team, not necessarily as its leader..." (my italics). Is it not time we dispelled this currently fashionable notion so widely advocated by the radical chic on TV and radio? The exclusion of the doctor from leading the team, assuming that a team is needed in all cases, leads to the omission of proper diagnostic methods, the consequent prognosis, and to the pitiful retreat implicit in the practice of subsequent care. The properly trained doctor is the only person capable of initiating the correct sorting out and selection of patients for investigation. And he is the only person capable of talking to relatives in a manner based on the full understanding of the patients' disease in its complex pathological,

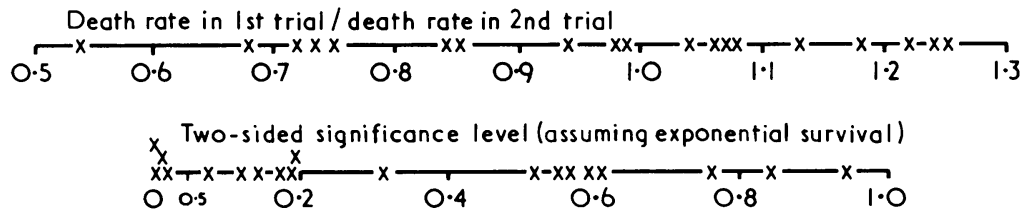

